\title{
Effectiveness of exercise intervention on fall-related fractures in older adults: a systematic review and meta-analysis of randomized controlled trials
}

Qiang Wang ${ }^{\dagger}$, Xiaowei Jiang ${ }^{*}{ }^{\dagger}$, Yingchao Shen ${ }^{\dagger}$, Ping Yao, Jun Chen, Yuan Zhou, Yunfeng Gu, Zhiyuan Qian and $\mathrm{Xi} \mathrm{CaO}$

\begin{abstract}
Background: Exercise intervention can significantly improve physical function and bone strength; however, the effect of exercise on fall-related fractures in older adults remains controversial. This study aimed to assess the effectiveness of exercise intervention on fall-related fractures in older adults by conducting a meta-analysis of randomized controlled trials (RCTs).
\end{abstract}

Methods: PubMed, EMBASE, and Cochrane databases were systematically searched for RCTs through November 24, 2019 to investigate the effectiveness of exercise intervention on fall-related fractures in older adults. Pooled relative risk (RR) with 95\% confidence interval (Cl) was calculated using the random-effects model. Sensitivity, subgroup, and publication bias analyses were also conducted.

Results: A total of 7704 older adults and 428 fall-related fracture events from 20 RCTs were selected for the final meta-analysis. The follow-up duration across included trials ranged from 6.0 months to 7.0 years. The pooled RR suggested that exercise intervention was associated with a reduced fall-related fracture risk in older adults (RR: 0.74; 95\% Cl: $0.59-0.92 ; P=0.007 ; P^{2}=12.6 \%$ ). The pooled conclusion was robust and not affected by any individual trial. Subgroup analysis revealed that the significant effect of exercise intervention on fall-related fractures was mainly detected when the study reported results from both male and female subjects, when it did not report the baseline body mass index, when individuals received both home- and center-based interventions, when the follow-up duration was $>1.0$ year, and when it was a high-quality study.

Conclusions: Regular exercise intervention could prevent fall-related fractures in older adults. Further large-scale RCTs should be conducted to assess the effectiveness of different exercise programs on fall-related fractures at various sites.

Keywords: Exercise, Fracture risk, Older adults, Meta-analysis

\footnotetext{
* Correspondence: renxiong02@126.com

${ }^{\dagger}$ Qiang Wang, Xiaowei Jiang and Yingchao Shen are co-first authors and contributed equally to this article.

Department of Orthopaedics, Changshu Hospital Affiliated to Nanjing

University of Chinese Medicine, No. 6 Huanghe Road, Changshu 215500,

China
}

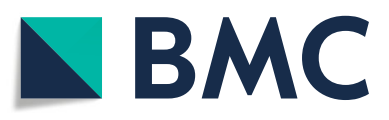

(0) The Author(s). 2020 Open Access This article is licensed under a Creative Commons Attribution 4.0 International License, which permits use, sharing, adaptation, distribution and reproduction in any medium or format, as long as you give appropriate credit to the original author(s) and the source, provide a link to the Creative Commons licence, and indicate if changes were made. The images or other third party material in this article are included in the article's Creative Commons licence, unless indicated otherwise in a credit line to the material. If material is not included in the article's Creative Commons licence and your intended use is not permitted by statutory regulation or exceeds the permitted use, you will need to obtain permission directly from the copyright holder. To view a copy of this licence, visit http://creativecommons.org/licenses/by/4.0/. The Creative Commons Public Domain Dedication waiver (http://creativecommons.org/publicdomain/zero/1.0/) applies to the data made available in this article, unless otherwise stated in a credit line to the data. 


\section{Background}

Falling is the most common cause of fractures in older adults, and fall-related injuries are the leading cause of increased hospitalization and medical costs [1-3]. Fractures occurred in older adults could affect the activities of daily living, even mortality in serious cases $[4,5]$. Nearly one-third of the individuals aged $\geq 65$ years fall each year, with $22-45 \%$ sustaining injuries and onetenth sustaining severe injuries such as a fracture or head injury [6-8]. Injurious falls and fractures cause long-lasting functional decline and taking care of such older adults becomes increasingly difficult $[9,10]$.

Several risk factors for falls and fall-induced injuries have already been demonstrated, which are related to physical inactivity and decreased functional capacity. These factors could be modified by physical activity [11]. However, frequent walking might increase fracture risk in older adults because of increased exposure to fall hazards [12]. The association between exercise intervention and reduced fall risk in older adults has already studied [13-15]. Moreover, numerous systematic review and meta-analyses have already been performed to investigate the role of exercise interventions on the risk of falls, injurious falls, and fractures [16-21]. However, previous studies did not focus on fall-related fractures [16-19, 21 ], and one study showed a pooled result based on 15 randomized controlled trials (RCTs) [20]. Therefore, the present meta-analysis of RCTs was conducted to assess the effect of exercise intervention on fall-related fractures in older adults.

\section{Methods}

\section{Data sources, search strategy, and selection criteria}

This study was conducted and reported in accordance to the Preferred Reporting Items for Systematic Reviews and Meta-Analysis Statement issued in 2009 [22]. This systematic review and meta-analysis of RCTs investigated the effectiveness of exercise intervention on fall-related fractures in older adults; no restrictions were placed on publication language and status. The electronic databases of PubMed, EMBASE, and Cochrane library were systematically searched for studies through November 24, 2019 using the core search terms "exercise" AND "fracture," then filtered with "clinical trial" and "Adult: 19-44 years aged $>65$ years." The details of search strategy in PubMed are presented in Supplement 1. The reference lists of retrieved studies were reviewed by manual searches to select any additional eligible study.

Two reviewers independently conducted the literature search and study selection. The selection process was based on the participants, intervention, control, outcome, and study design (PICOS). Any disagreement between the two reviewers was resolved by discussion until a consensus. A study was included if it met the following inclusion criteria: (1) study design: RCT; (2) participants: adults aged $\geq 50.0$ years; (3) intervention: exercise program without the use of hormone replacement therapy, glucocorticoids, or bisphosphonates; (4) control: usual care; and (5) outcome: fall-related fracture incidence, irrespective of the site. Studies designed as observational studies, meta-analyses, letters to the editors, and animal studies were excluded.

\section{Data collection and quality assessment}

Two reviewers assessed the abstracted data and study quality following a standardized extraction form, and any disagreement was resolved by an additional author referring to the original article until a consensus was reached. The abstracted items included the first author's name; publication year; country; sample size; mean age; the percentage of male subjects; body mass index (BMI); the number of fall-related fractures, exercise regimens, controls, supplements; and follow-up duration. The quality of included studies was evaluated using the Jadad scale based on randomization, blinding, allocation concealment, withdrawals and dropouts, and the use of intention-to-treat analysis [23]. Each item was assigned as "yes," "no," or "not mentioned", and the scoring system ranged from 0 to 5 . An RCT score of 4 or 5 indicated high quality.

\section{Statistical analysis}

The effectiveness of exercise intervention on fall-related fractures in older adults was assigned as categorical data, and relative risk (RR) with 95\% confidence interval (CI) was applied as an effect estimate. Pooled RR with 95\% CI was calculated using the random-effects model due to the underlying variations across the included studies $[24,25]$. Heterogeneity across included trials was assessed using $I^{2}$ and Q statistics, and significant heterogeneity was defined as $I^{2}>50.0 \%$ or $P<0.10[26,27]$. Sensitivity analysis was used for assessing the robustness of pooled conclusions [28]. Subgroup analysis for fracture risk was conducted according to the mean age ( $\geq 70.0$ years or $<70.0$ years), sex (female or both), BMI $\left(\geq 25.0 \mathrm{~kg} / \mathrm{m}^{2}\right.$ or $\left.<25.0 \mathrm{~kg} / \mathrm{m}^{2}\right)$, intervention (homebased, center-based, or both), follow-up duration ( $\geq 1.0$ years or $<1.0$ years), and study quality (high or low), and the difference between subgroups was analyzed using $P$-test for interaction [29]. Publication bias was assessed qualitatively using funnel plot and quantitatively using the Egger's and Begg's tests [30, 31]. The inspection level was two-sided, and $P<0.05$ was considered as significant. Statistical analyses were conducted using STATA (version 10.0; Stata Corporation, College Station, TX, USA). 


\section{Results}

Literature search

A total of 4026 articles were identified from initial electronic searches, of which 1879 were excluded because they were duplicates. An additional 2066 studies were excluded due to the topics being irrelevant. The remaining 81 studies were retrieved for further full-text evaluations; 61 studies were excluded after detailed evaluations. The following were the reasons for exclusion: study did not report fracture incidence $(n=43)$, study did not use RCT design $(n=7)$, and study included other interventions $(n=11)$. A manual search of the reference lists of retrieved studies yielded 7 studies; all studies were contained in electronic searches. Finally, 20 RCTs were selected for the final meta-analysis (Fig. 1) [32-51]. Table 1 summarizes the baseline characteristics of the included studies.

\section{Study characteristics}

A total of 7704 older adults and 428 fall-related fracture events from 20 RCTs were included. The publication year of the included studies ranged from 1996 to 2019 , and 20-1635 individuals were included in each trial. Overall, 13 studies were conducted in Europe and the remaining seven were conducted in Australia, New Zealand, China, USA, and Canada. A total of nine studies included only females and the remaining 11 included both males and females. Study quality was assessed using the Jadad scale: 13 studies scored 5, three studies scored 4 , two studies scored 3, and the remaining two studies scored 2 (Table 2).

\section{Meta-analysis}

All included studies reported fracture incidence in the exercise and control groups, and the RR across the included trials ranged from 0.19 to 3.00 . The pooled RR indicated that exercise intervention significantly reduced fall-related fracture risk (RR: 0.74; 95\% CI: 0.59-0.92; $P=0.007$; Fig. 2). Moreover, unimportant heterogeneity was observed across the included trials $\left(I^{2}=12.6 \%\right.$; $P=$ 0.298). According to the sensitivity analysis, the pooled

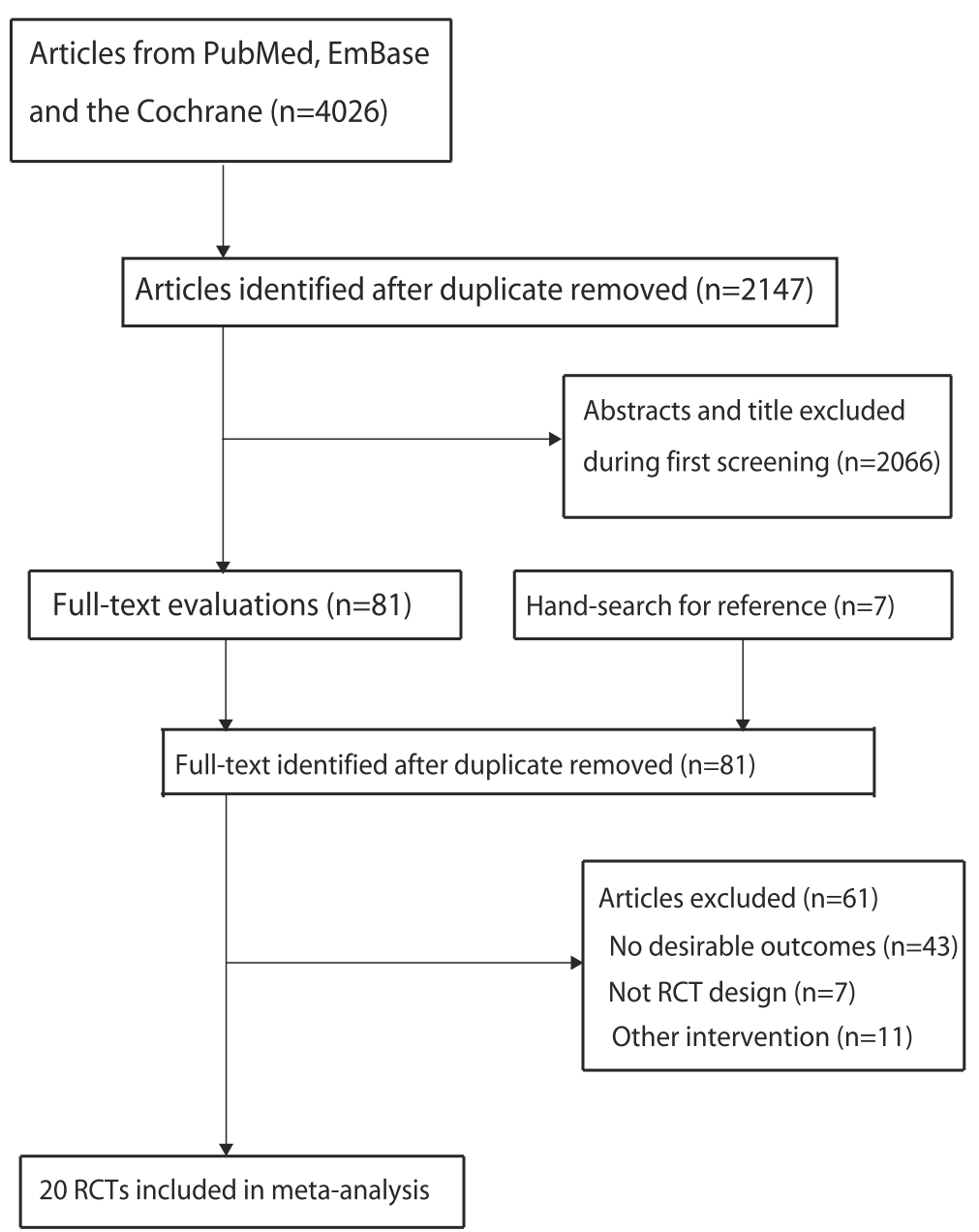

Fig. 1 The Preferred Reporting Items for Systematic Reviews and Meta-Analysis Statement (PRISMA) flowchart describing our literature search 


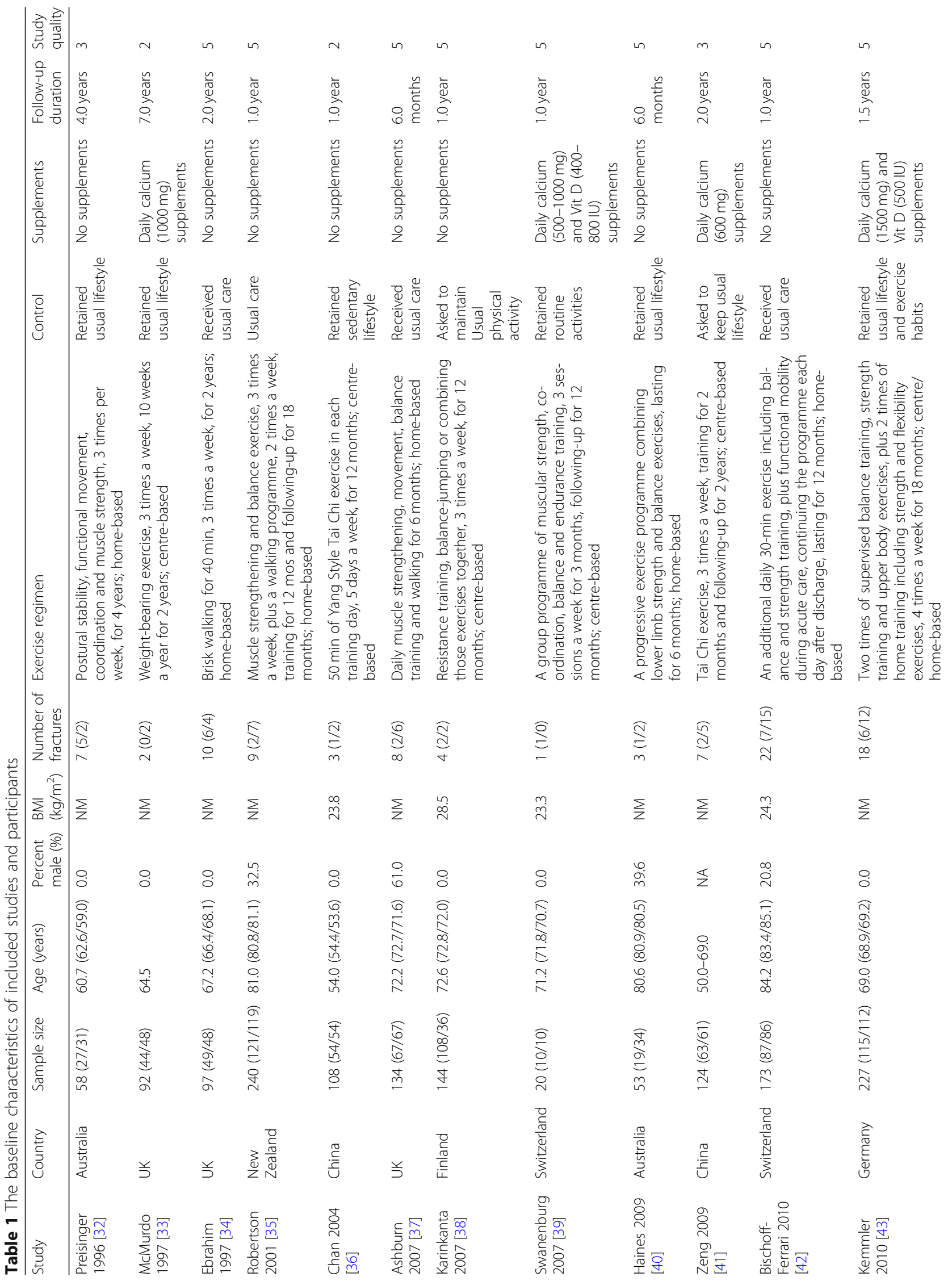




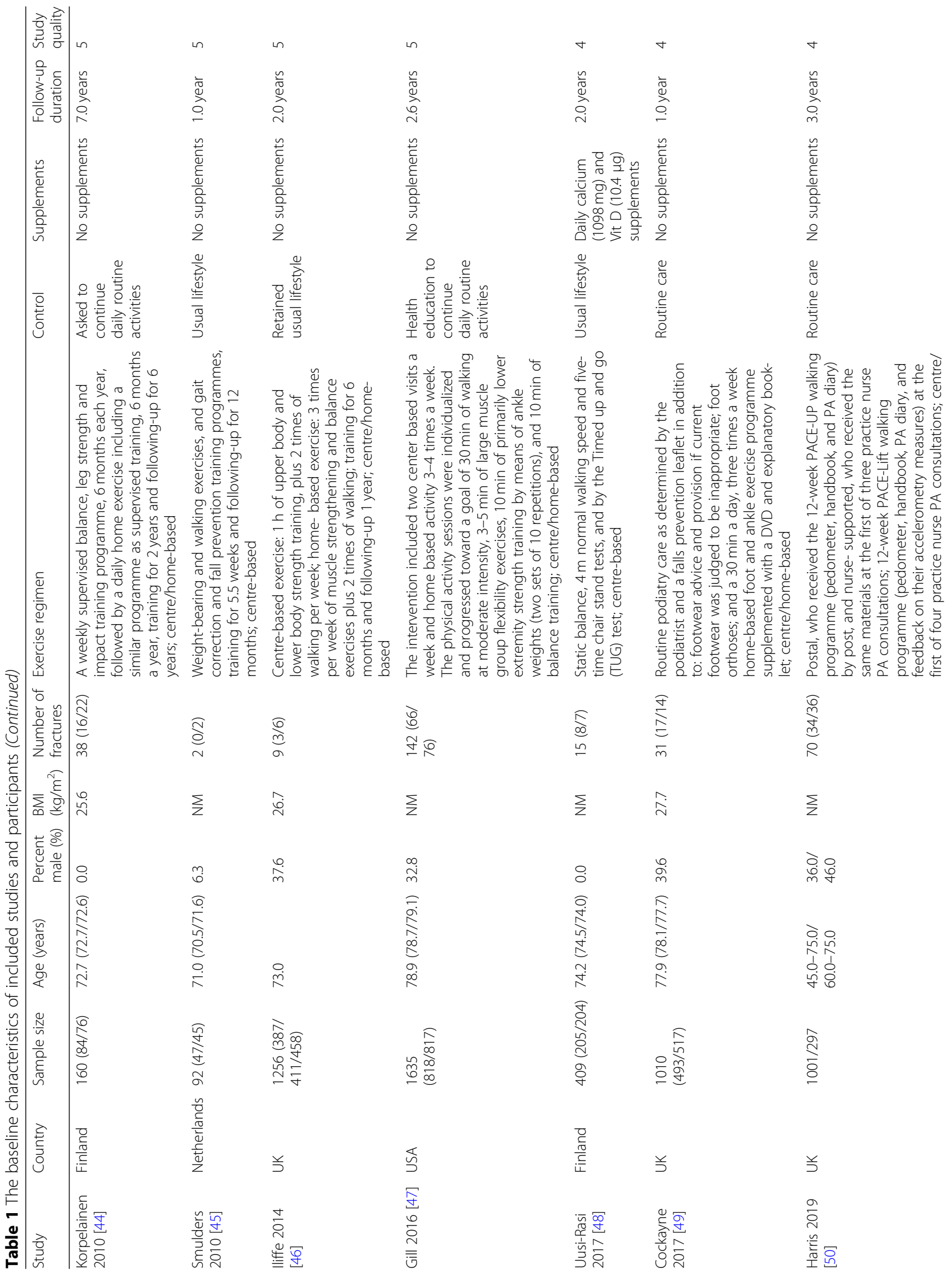




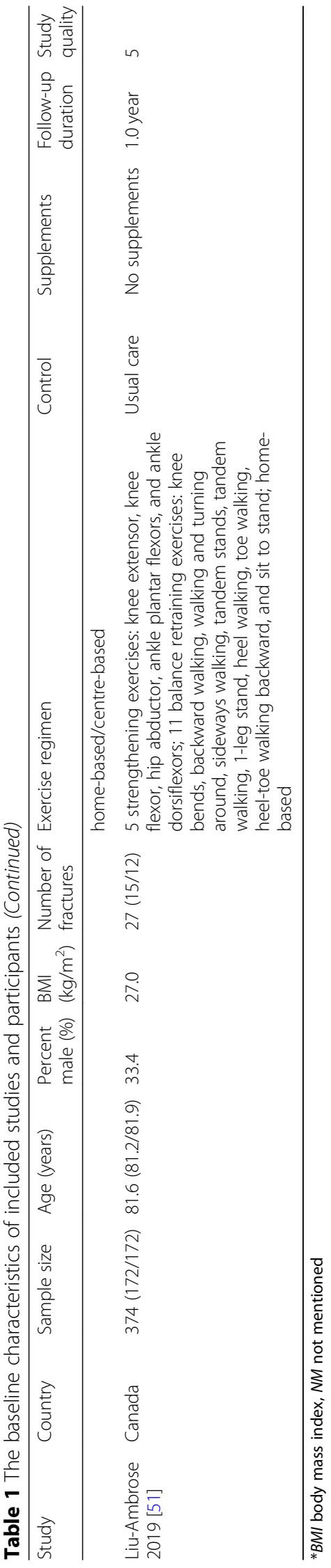


Table 2 Assessment of risk of bias in included studies

\begin{tabular}{|c|c|c|c|c|c|c|}
\hline Study & Randomization & Blinding & Allocation concealment & Withdrawals and dropouts & Use of intention-to-treat analysis & Overall \\
\hline Preisinger 1996 [32] & Yes & Yes & Unclear & Yes & Unclear & 3 \\
\hline McMurdo 1997 [33] & Yes & Unclear & Unclear & Unclear & Yes & 2 \\
\hline Ebrahim 1997 [34] & Yes & Yes & Yes & Yes & Yes & 5 \\
\hline Robertson 2001 [35] & Yes & Yes & Yes & Yes & Yes & 5 \\
\hline Chan 2004 [36] & Yes & Unclear & Unclear & Unclear & Yes & 2 \\
\hline Ashburn 2007 [37] & Yes & Yes & Yes & Yes & Yes & 5 \\
\hline Karinkanta 2007 [38] & Yes & Yes & Yes & Yes & Yes & 5 \\
\hline Swanenburg 2007 [39] & Yes & Yes & Yes & Yes & Yes & 5 \\
\hline Haines 2009 [40] & Yes & Yes & Yes & Yes & Yes & 5 \\
\hline Zeng 2009 [41] & Yes & Unclear & Unclear & Yes & Yes & 3 \\
\hline Bischoff-Ferrari 2010 [42] & Yes & Yes & Yes & Yes & Yes & 5 \\
\hline Kemmler 2010 [43] & Yes & Yes & Yes & Yes & Yes & 5 \\
\hline Korpelainen 2010 [44] & Yes & Yes & Yes & Yes & Yes & 5 \\
\hline Smulders 2010 [45] & Yes & Yes & Yes & Yes & Yes & 5 \\
\hline Iliffe 2014 [46] & Yes & Yes & Yes & Yes & Yes & 5 \\
\hline Gill 2016 [47] & Yes & Yes & Yes & Yes & Yes & 5 \\
\hline Uusi-Rasi 2017 [48] & Yes & Yes & Unclear & Yes & Yes & 4 \\
\hline Cockayne 2017 [49] & Yes & Yes & Unclear & Yes & Yes & 4 \\
\hline Harris 2019 [50] & Yes & Yes & Unclear & Yes & Yes & 4 \\
\hline Liu-Ambrose 2019 [51] & Yes & Yes & Yes & Yes & Yes & 5 \\
\hline
\end{tabular}

conclusion was robust and did not change after sequentially excluding individual trials (Fig. 3).

\section{Subgroup analysis}

Subgroup analysis for fall-related fracture risk between exercise intervention and usual care was also performed. Exercise intervention was associated with reduced fall-related fractures when the study reported both males and females (RR: 0.69; 95\% CI: $0.51-0.94 ; P=0.019)$, when the study did not report the baseline BMI (RR: 0.72; 95\% CI: 0.53-0.96; $P=$ $0.024)$, when individuals received both home- and centerbased interventions (RR: 0.71; 95\% CI: 0.53-0.96; $P=0.025$ ),

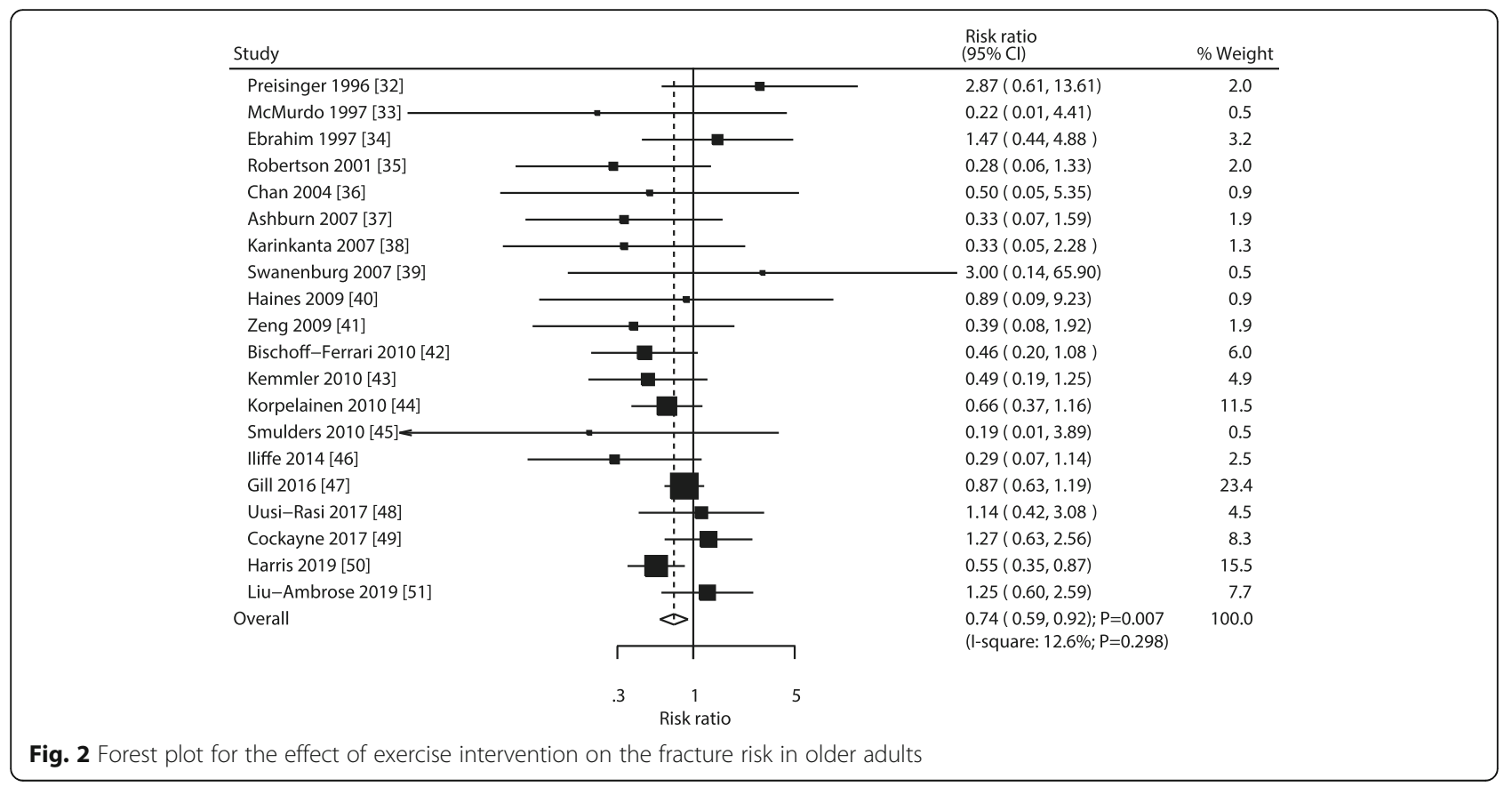




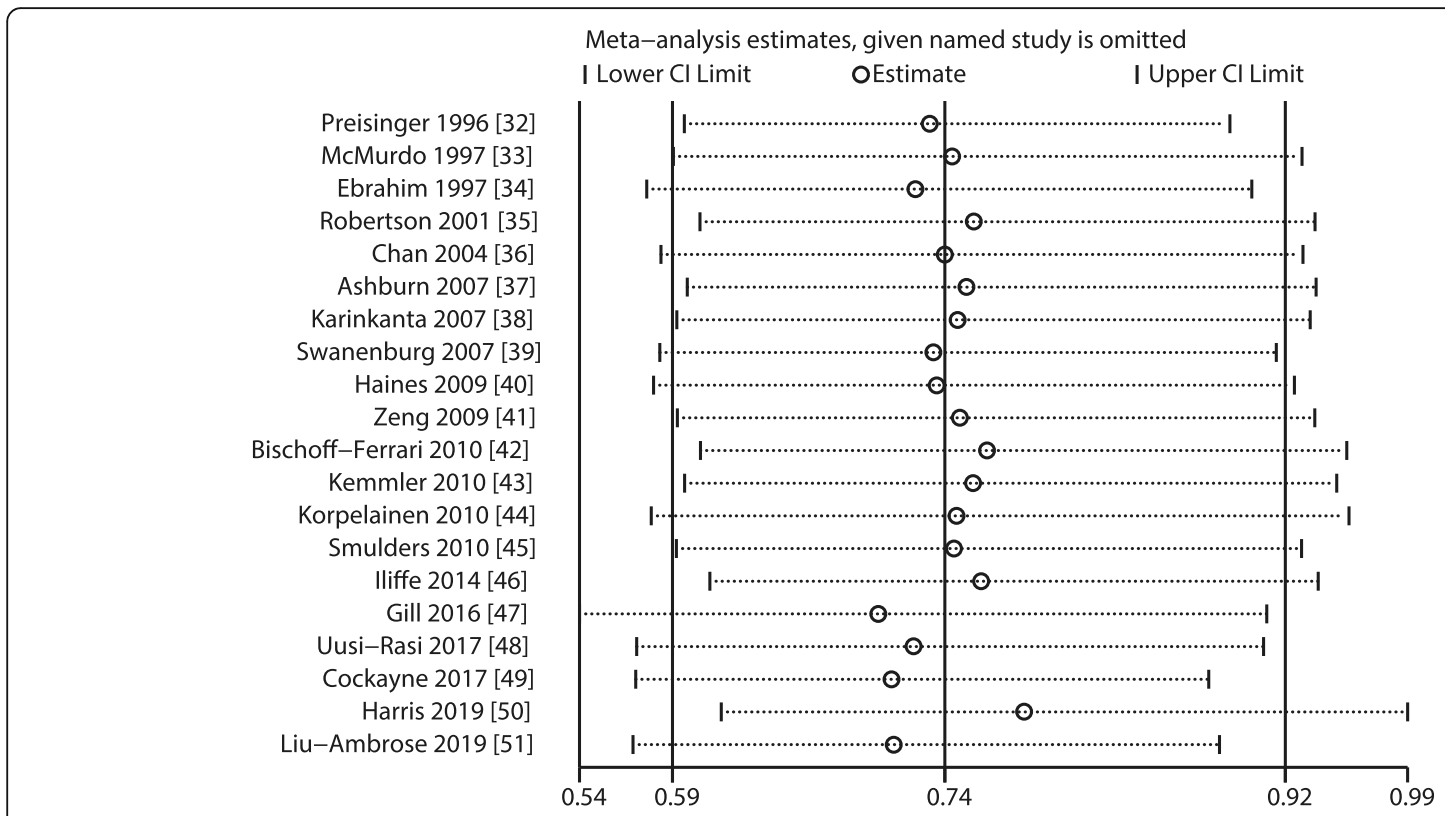

Fig. 3 Sensitivity analysis for the fracture risk by sequentially excluding each individual trial

when the follow-up duration was > 1.0 year (RR: 0.72; 95\% CI: $0.55-0.95 ; P=0.022)$, and when it was a high-quality study (RR: $0.73 ; 95 \%$ CI: $0.58-0.92 ; P=$ 0.007 ). No other significant difference was observed, and the difference between subgroups was not significant, irrespective of stratification by mean age, sex, BMI, intervention, or study quality (Table 3 ).

\section{Publication Bias}

Publication bias could not be ruled out by reviewing the funnel plot (Fig. 4). Moreover, the Egger's $(P=0.349)$ and Begg's test $(P=0.974)$ results suggested no evidence of publication bias among included trials.

\section{Discussion}

The present study aimed to compare the effectiveness of exercise intervention in reducing fall-related fractures in older adults. This comprehensive quantitative metaanalysis included 7704 older adults and reported 428 fall-related fracture events from 20 RCTs across a broad range of individual characteristics. The findings of this study suggested that exercise intervention reduces fall-

Table 3 Subgroup analysis for the risk of fracture

\begin{tabular}{|c|c|c|c|c|c|c|}
\hline Factors & Subgroup & $\mathrm{RR}$ and $95 \% \mathrm{Cl}$ & $P$ value & Heterogeneity (\%) & $P$ value for heterogeneity & $P$ value between subgroups \\
\hline \multirow[t]{2}{*}{ Mean age (years) } & $\geq 70.0$ & $0.78(0.60-1.01)$ & 0.057 & 10.6 & 0.339 & \multirow[t]{2}{*}{0.253} \\
\hline & $<70.0$ & $0.66(0.42-1.04)$ & 0.075 & 14.4 & 0.320 & \\
\hline \multirow[t]{2}{*}{ Gender } & Female & $0.78(0.53-1.13)$ & 0.193 & 0.0 & 0.440 & \multirow[t]{2}{*}{0.866} \\
\hline & Both & $0.69(0.51-0.94)$ & 0.019 & 27.4 & 0.183 & \\
\hline \multirow[t]{3}{*}{ BMI $\left(\mathrm{kg} / \mathrm{m}^{2}\right)$} & $\geq 25.0$ & $0.81(0.50-1.33)$ & 0.406 & 38.0 & 0.168 & \multirow[t]{3}{*}{0.537} \\
\hline & $<25.0$ & $0.52(0.24-1.13)$ & 0.100 & 0.0 & 0.517 & \\
\hline & Not mentioned & $0.72(0.53-0.96)$ & 0.024 & 13.5 & 0.312 & \\
\hline \multirow[t]{3}{*}{ Intervention } & Home-based & $0.82(0.45-1.47)$ & 0.500 & 37.3 & 0.144 & \multirow[t]{3}{*}{0.829} \\
\hline & Center-based & $0.66(0.34-1.30)$ & 0.233 & 0.0 & 0.648 & \\
\hline & Both & $0.71(0.53-0.96)$ & 0.025 & 34.0 & 0.181 & \\
\hline \multirow[t]{2}{*}{ Follow-up duration (years) } & $\leq 1.0$ & $0.75(0.48-1.15)$ & 0.185 & 12.4 & 0.329 & \multirow[t]{2}{*}{0.779} \\
\hline & $>1.0$ & $0.72(0.55-0.95)$ & 0.022 & 20.9 & 0.250 & \\
\hline \multirow[t]{2}{*}{ Study quality } & High & $0.73(0.58-0.92)$ & 0.007 & 14.1 & 0.292 & \multirow[t]{2}{*}{0.883} \\
\hline & Low & $0.75(0.23-2.46)$ & 0.636 & 29.4 & 0.236 & \\
\hline
\end{tabular}




\section{Funnel plot with pseudo 95\% confidence limits}

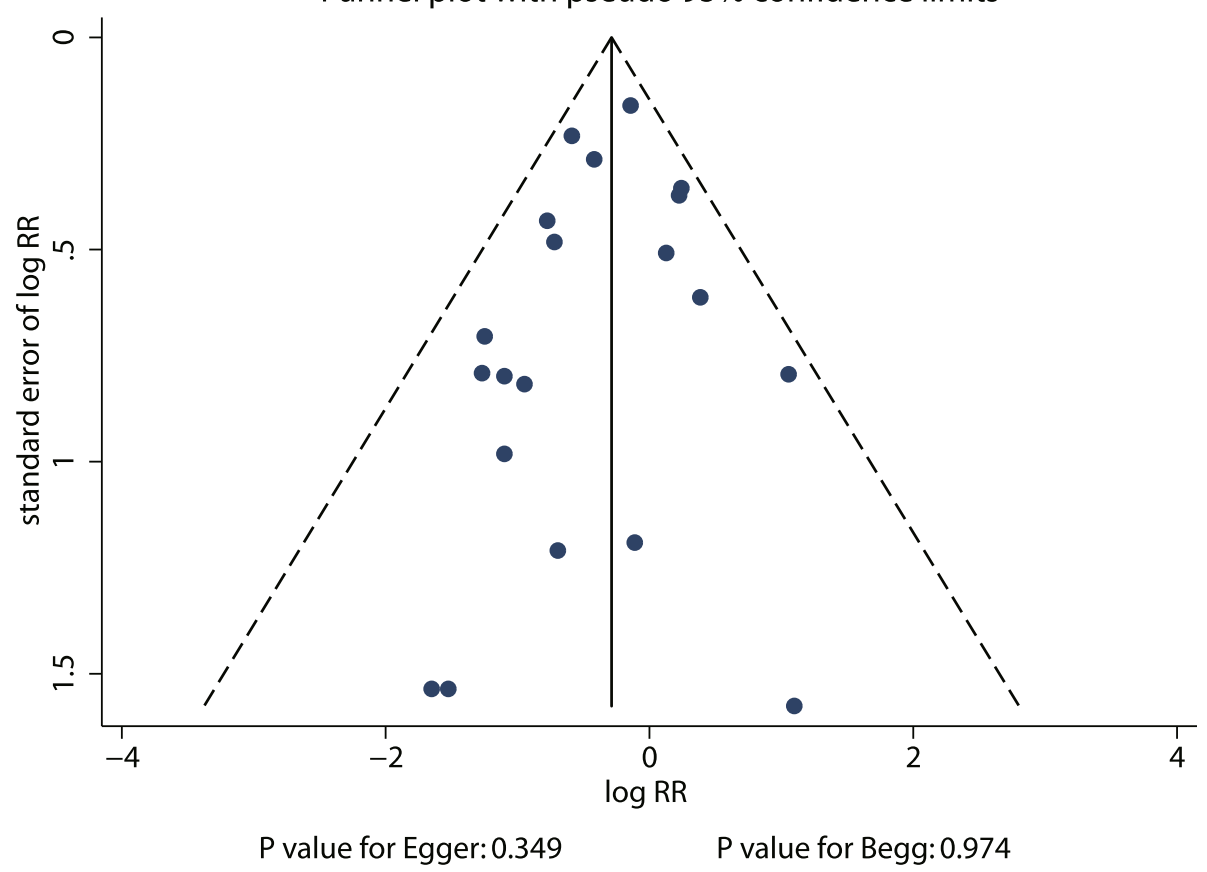

Fig. 4 Publication bias test results

related fractures in older adults. It might be anticipated that exercise interventions should be used in older adults for preventing fall-related fractures.

Several systematic reviews and meta-analyses have already described the role of exercise intervention in older adults. Jepsen et al. found that whole-body vibration exercise significantly reduced fall risk [16]. Hill et al. found that exercise intervention had no significant effect on the risk of injurious falls or fractures, although the physical activity, balance, mobility, and muscle strength were significantly improved [17]. Silva et al. suggested that fall risk was significantly decreased when individuals participated in frequent and long-term exercise programs, whereas the fracture risk was not affected by exercise intervention [18]. Kemmler et al. found that the fracture risk was significantly reduced in older adults who participated in exercise interventions [19]. de Souto Berreto et al. pointed out that long-term exercise interventions significantly reduced the incidences of falls, injurious falls, and probable fractures in older adults [21]. The above studies did not focus on fall-related fracture risk in individuals who underwent exercise interventions. A meta-analysis conducted by Zhao et al. included 15 RCTs and found that the risk of fall-related fracture risk, falls, and leg strength were significantly improved in older adults who underwent exercise interventions [20]. However, this study just provided a pooled result between exercise and control for fall-related fracture risk, and whether the treatment effects between exercise and control for fall-related fracture risk differed according to patients' characteristics was not illustrated [21]. Furthermore, additional five studies have already been published, and the results should have been re-evaluated [47-51]. Although most findings of this study were consistent with a prior meta-analysis [20], the exploratory results of subgroup analysis found significant effects of exercise intervention on the fall-related fracture risk mainly detected when the study reported both male and female subjects, when the study that did not reported baseline BMI, when individuals received both home- and center-based interventions, when the follow-up duration was $>1.0$ year, and when it was a high-quality study.

Although most included trials reported similar trends for the protective role of exercise intervention in older adults, several trials reported inconsistent results. Preisinger et al. found that the incidence of vertebral fracture in the exercise group was lower than that in the usual care group, whereas the incidence of fragility fracture in the exercise group was higher than that in the usual care group [32]. These results could be explained by the type of exercise program and the smaller number of events. Ebrahim et al. found that the fracture incidence within 2 years was higher in the exercise group than in the usual care group (6 vs. 4) [34]. The potential reason for this could be the compliance of individuals, risk of injuries, and the intensity of exercise, balancing the potential benefit on fall-related fracture risk. Swanenburg et al. reported that within 12 months, one case 
fracture was reported in the exercise group and none in the control group; the reason for this was shorter duration and the magnitude of the event occurred was lower than expected [39]. Uusi-Rasi et al. found that fractures related to falls were similar between the exercise and control groups [48]. This result could be explained by the improvement of lower extremity function, mobility, and balance in older adults who underwent exercise interventions $[52,53]$. Cockayne et al. found that incidence of fractures in the multifaceted podiatry intervention group was higher than that in the usual care group (17 vs. 14), which may correlate with the type of exercise program [49]. LiuAmbrose et al. found that individuals who participated in five strengthening exercises and 11 balance retraining exercises may be at an increased fracture risk (RR: 1.93). The potential reason is that older adults with vigorous exercise intervention show low compliance and high incidence of injuries, and low exercise intensity may show limited effects in older adults [54].

Subgroup analyses were conducted, and the results indicated that the beneficial effects of exercise intervention were mainly detected when the study reported both male and female subjects, when the study that did not reported baseline BMI, when individuals received both home- and center-based interventions, when the followup duration was $>1.0$ year, and when it was a highquality study. There were several reasons for these results: (1) the incidence of fall-related fracture was lower, and the statistical power in several subgroups was not enough to detect potential differences between the exercise and control groups; (2) the intensity of the exercise program could affect the net effects of exercise on fallrelated fractures in older adults; (3) long-term exercise interventions were associated with a reduced incidence of falls in older adults, which could prevent fall-related fractures; and (4) the quality of studies could affect the reliability of individual trials, and this analysis mostly included studies with high quality.

Several limitations of this study should be acknowledged. First, the type and volume of exercise program varies across included trials, which could affect the progression of fall-related fractures. Second, stratified analyses were conducted based on the pooled characteristics of study or patients, and the results stratified by the details of individuals' characteristics were not available. Third, the analysis of this study was based on published articles, and publication bias was inevitable.

\section{Conclusion}

In conclusion, exercise is an important strategy to decrease fall-related fractures in older adults. Future largescale RCTs should be conducted to verify the effectiveness of exercise intervention on fall-related fractures at various sites.

\section{Supplementary information}

Supplementary information accompanies this paper at https://doi.org/10. 1186/s12877-020-01721-6.

Additional file 1. Supplemental 1 Search Strategy For Pubmed

Abbreviations

RCTs: randomized controlled trials; RR: relative risk; $\mathrm{Cl}$ : confidence interval

\section{Acknowledgements}

Not applicable.

\section{Authors' contributions}

QW chose the subject and designed the study; XWJ chose the subject and wrote the paper; YCS revised the paper and supported the data; PY contributed to the data analysis; and ZYQ, YZ, YFG, JC and XC contributed to the data acquisition. All authors read and approved the final manuscript.

\section{Funding}

Not applicable.

Availability of data and materials

All data generated or analyzed during this study are included in this published article and its supplementary information files.

Ethics approval and consent to participate

Not applicable.

Consent for publication

Not applicable.

\section{Competing interests}

The authors declare that they have no competing interests.

Received: 3 January 2020 Accepted: 19 August 2020

Published online: 04 September 2020

\section{References}

1. Ambrose AF, Cruz L, Paul G. Falls and fractures: a systematic approach to screening and prevention. Maturitas. 2015;82(1):85-93.

2. Kannus $P$, Sievanen $H$, Palvanen $M$, Jarvinen $T$, Parkkari J. Prevention of falls and consequent injuries in elderly people. Lancet. 2005;366(9500):1885-93.

3. Stevens JA, Corso PS, Finkelstein EA, Miller TR. The costs of fatal and nonfatal falls among older adults. Inj Prev. 2006;12(5):290-5.

4. Nguyen ND, Center JR, Eisman JA, Nguyen TV. Bone loss, weight loss, and weight fluctuation predict mortality risk in elderly men and women. J Bone Miner Res. 2007;22(8):1147-54.

5. Suzuki T, Yoshida H. Low bone mineral density at femoral neck is a predictor of increased mortality in elderly Japanese women. Osteoporos Int. 2010;21(1):71-9.

6. Tinetti ME. Clinical practice. Preventing falls in elderly persons. N Engl J Med. 2003;348(1):42-9.

7. Korhonen N, Niemi S, Parkkari J, Sievanen H, Kannus P. Incidence of fallrelated traumatic brain injuries among older Finnish adults between 1970 and 2011. JAMA. 2013;309(18):1891-2.

8. Luukinen H, Koski K, Honkanen R, Kivela SL. Incidence of injury-causing falls among older adults by place of residence: a population-based study. J Am Geriatr Soc. 1995;43(8):871-6.

9. Gill TM, Murphy TE, Gahbauer EA, Allore HG. The course of disability before and after a serious fall injury. JAMA Intern Med. 2013;173(19):1780-6.

10. Svedbom A, Ivergard M, Hernlund E, Rizzoli R, Kanis JA. Epidemiology and economic burden of osteoporosis in Switzerland. Arch Osteoporos. 2014;9: 187.

11. Karinkanta S, Piirtola M, Sievanen H, Uusi-Rasi K, Kannus P. Physical therapy approaches to reduce fall and fracture risk among older adults. Nat Rev Endocrinol. 2010;6(7):396-407.

12. Appleby PN, Allen NE, Roddam AW, Key TJ. Physical activity and fracture risk: a prospective study of 1898 incident fractures among 34,696 British men and women. J Bone Miner Metab. 2008;26(2):191-8. 
13. Finnegan S, Seers K, Bruce J. Long-term follow-up of exercise interventions aimed at preventing falls in older people living in the community: a systematic review and meta-analysis. Physiotherapy. 2019;105(2):187-99.

14. Sherrington C, Fairhall NJ, Wallbank GK, Tiedemann A, Michaleff ZA, Howard K, Clemson L, Hopewell S, Lamb SE. Exercise for preventing falls in older people living in the community. Cochrane Database Syst Rev. 2019;1:Cd012424.

15. Sherrington C, Michaleff ZA, Fairhall N, Paul SS, Tiedemann A, Whitney J, Cumming RG, Herbert RD, Close JCT, Lord SR. Exercise to prevent falls in older adults: an updated systematic review and meta-analysis. Br J Sports Med. 2017:51(24):1750-8.

16. Jepsen DB, Thomsen K, Hansen S, Jorgensen NR, Masud T, Ryg J. Effect of whole-body vibration exercise in preventing falls and fractures: a systematic review and meta-analysis. BMJ Open. 2017;7(12):e018342.

17. Hill KD, Hunter SW, Batchelor FA, Cavalheri V, Burton E. Individualized homebased exercise programs for older people to reduce falls and improve physical performance: a systematic review and meta-analysis. Maturitas. 2015;82(1):72-84

18. Silva RB, Eslick GD, Duque G. Exercise for falls and fracture prevention in long term care facilities: a systematic review and meta-analysis. J Am Med Dir Assoc. 2013:14(9):685-9 e682.

19. Kemmler W, Haberle L, von Stengel S. Effects of exercise on fracture reduction in older adults: a systematic review and meta-analysis. Osteoporos Int. 2013;24(7):1937-50

20. Zhao R, Feng F, Wang X. Exercise interventions and prevention of fallrelated fractures in older people: a meta-analysis of randomized controlled trials. Int J Epidemiol. 2017;46(1):149-61.

21. de Souto BP, Rolland Y, Vellas B, Maltais M. Association of Long-term Exercise Training with Risk of falls, fractures, hospitalizations, and mortality in older adults: a systematic review and meta-analysis. JAMA Intern Med. 2019; 179(3):394-405.

22. Moher D, Liberati A, Tetzlaff J, Altman DG. Preferred reporting items for systematic reviews and meta-analyses: the PRISMA statement. PLoS Med. 2009;6(7):e1000097.

23. Jadad AR, Moore RA, Carroll D, Jenkinson C, Reynolds DJ, Gavaghan DJ, McQuay HJ. Assessing the quality of reports of randomized clinical trials: is blinding necessary? Control Clin Trials. 1996;17(1):1-12.

24. DerSimonian R, Laird N. Meta-analysis in clinical trials. Control Clin Trials. 1986;7(3):177-88.

25. Ades $A E$, Lu G, Higgins JP. The interpretation of random-effects metaanalysis in decision models. Med Decis Mak. 2005;25(6):646-54.

26. Deeks JJ, Higgins JP, Altman DG. Analysing data and undertaking metaanalyses. Cochrane Hand Syst Rev Int. 2008:241-84.

27. Higgins JP, Thompson SG, Deeks JJ, Altman DG. Measuring inconsistency in meta-analyses. BMJ. 2003;327(7414):557-60.

28. Tobias A. Assessing the influence of a single study in the meta-analysis estimate. Stata Tech Bull. 1999;47:15-7.

29. Altman DG, Bland JM. Interaction revisited: the difference between two estimates. BMJ. 2003:326(7382):219.

30. Egger M, Davey Smith G, Schneider M, Minder C. Bias in meta-analysis detected by a simple, graphical test. BMJ. 1997;315(7109):629-34.

31. Begg CB, Mazumdar M. Operating characteristics of a rank correlation test for publication bias. Biometrics. 1994;50(4):1088-101.

32. Preisinger E, Alacamlioglu Y, Pils K, Bosina E, Metka M, Schneider B, Ernst E. Exercise therapy for osteoporosis: results of a randomised controlled trial. $\mathrm{Br}$ J Sports Med. 1996;30(3):209-12.

33. McMurdo ME, Mole PA, Paterson CR. Controlled trial of weight bearing exercise in older women in relation to bone density and falls. BMJ. 1997;314(7080):569.

34. Ebrahim S, Thompson PW, Baskaran V, Evans K. Randomized placebocontrolled trial of brisk walking in the prevention of postmenopausal osteoporosis. Age Ageing. 1997;26(4):253-60.

35. Robertson MC, Devlin N, Gardner MM, Campbell AJ. Effectiveness and economic evaluation of a nurse delivered home exercise programme to prevent falls. 1: randomised controlled trial. BMJ. 2001;322(7288):697-701.

36. Chan K, Qin L, Lau M, Woo J, Au S, Choy W, Lee K, Lee S. A randomized, prospective study of the effects of tai chi Chun exercise on bone mineral density in postmenopausal women. Arch Phys Med Rehabil. 2004;85(5):717-22.

37. Ashburn A, Fazakarley L, Ballinger C, Pickering R, McLellan LD, Fitton C. A randomised controlled trial of a home based exercise programme to reduce the risk of falling among people with Parkinson's disease. J Neurol Neurosurg Psychiatry. 2007;78(7):678-84

38. Karinkanta S, Heinonen A, Sievanen H, Uusi-Rasi K, Pasanen M, Ojala K, Fogelholm M, Kannus P. A multi-component exercise regimen to prevent functional decline and bone fragility in home-dwelling elderly women: randomized, controlled trial. Osteoporos Int. 2007;18(4):453-62.

39. Swanenburg J, de Bruin ED, Stauffacher M, Mulder T, Uebelhart D. Effects of exercise and nutrition on postural balance and risk of falling in elderly people with decreased bone mineral density: randomized controlled trial pilot study. Clin Rehabil. 2007;21(6):523-34.

40. Haines TP, Russell T, Brauer SG, Erwin S, Lane P, Urry S, Jasiewicz J, Condie P. Effectiveness of a video-based exercise programme to reduce falls and improve health-related quality of life among older adults discharged from hospital: a pilot randomized controlled trial. Clin Rehabil. 2009;23(11):973-85.

41. Zeng Y, Zhu H, Guo L. The Effect of Tai Chi Exercise on Balance and Fractures in Older People. Hang Zhou: Rehabilitation Medicine Society of Chinese Medical Doctor Association; 2009.

42. Bischoff-Ferrari HA, Dawson-Hughes B, Platz A, Orav EJ, Stahelin HB, Willett WC, Can U, Egli A, Mueller NJ, Looser S, et al. Effect of high-dosage cholecalciferol and extended physiotherapy on complications after hip fracture: a randomized controlled trial. Arch Intern Med. 2010;170(9):813-20.

43. Kemmler W, von Stengel S, Engelke K, Haberle L, Kalender WA. Exercise effects on bone mineral density, falls, coronary risk factors, and health care costs in older women: the randomized controlled senior fitness and prevention (SEFIP) study. Arch Intern Med. 2010;170(2):179-85.

44. Korpelainen R, Keinanen-Kiukaanniemi S, Nieminen P, Heikkinen J, Vaananen K, Korpelainen J. Long-term outcomes of exercise: follow-up of a randomized trial in older women with osteopenia. Arch Intern Med. 2010; 170(17):1548-56

45. Smulders E, Weerdesteyn V, Groen BE, Duysens J, Eijsbouts A, Laan R, van Lankveld W. Efficacy of a short multidisciplinary falls prevention program for elderly persons with osteoporosis and a fall history: a randomized controlled trial. Arch Phys Med Rehabil. 2010;91(11):1705-11.

46. Iliffe S, Kendrick D, Morris R, Masud T, Gage H, Skelton D, Dinan S, Bowling A, Griffin M, Haworth D et al: Multicentre cluster randomised trial comparing a community group exercise programme and home-based exercise with usual care for people aged 65 years and over in primary care. Health Technol Assess 2014, 18(49):vii-xxvii, 1-105.

47. Gill TM, Pahor M, Guralnik JM, McDermott MM, King AC, Buford TW, Strotmeyer ES, Nelson ME, Sink KM, Demons JL, et al. Effect of structured physical activity on prevention of serious fall injuries in adults aged 70-89: randomized clinical trial (LIFE study). BMJ. 2016;352:i245.

48. Uusi-Rasi K, Patil R, Karinkanta S, Kannus P, Tokola K, Lamberg-Allardt C, Sievanen H. A 2-year follow-up after a 2-year RCT with vitamin D and exercise: effects on falls, injurious falls and physical functioning among older women. J Gerontol A Biol Sci Med Sci. 2017;72(9):1239-45.

49. Cockayne S, Adamson J, Clarke A, Corbacho B, Fairhurst C, Green L, Hewitt CE, Hicks K, Kenan AM, Lamb SE, et al. Cohort randomised controlled trial of a multifaceted podiatry intervention for the prevention of falls in older people (the REFORM trial). PLoS One. 2017;12(1):e0168712.

50. Harris T, Limb ES, Hosking F, Carey I, DeWilde S, Furness C, Wahlich C, Ahmad S, Kerry S, Whincup P, et al. Effect of pedometer-based walking interventions on long-term health outcomes: prospective 4-year follow-up of two randomised controlled trials using routine primary care data. PLoS Med. 2019;16(6):e1002836.

51. Liu-Ambrose T, Davis JC, Best JR, Dian L, Madden K, Cook W, Hsu CL, Khan KM. Effect of a home-based exercise program on subsequent falls among community-dwelling high-risk older adults after a fall: a randomized clinical trial. Jama. 2019:321(21):2092-100.

52. El-Khoury F, Cassou B, Charles MA, Dargent-Molina P. The effect of fall prevention exercise programmes on fall induced injuries in community dwelling older adults: systematic review and meta-analysis of randomised controlled trials. BMJ. 2013:347:f6234.

53. Gianoudis J, Bailey CA, Ebeling PR, Nowson CA, Sanders KM, Hill K, Daly RM. Effects of a targeted multimodal exercise program incorporating high-speed power training on falls and fracture risk factors in older adults: a community-based randomized controlled trial. J Bone Miner Res. 2014;29(1): 182-91.

54. Martin JE, Dubbert PM. Exercise applications and promotion in behavioral medicine: current status and future directions. J Consult Clin Psychol. 1982; 50(6):1004-17

\section{Publisher's Note}

Springer Nature remains neutral with regard to jurisdictional claims in published maps and institutional affiliations. 